\title{
Do Actions Speak Louder Than Words? The Response of Asset Prices to Monetary Policy Actions and Statements*
}

\author{
Refet S. Gürkaynak, ${ }^{\text {a,c }}$ Brian Sack, ${ }^{\mathrm{b}}$ and Eric T. Swanson ${ }^{\mathrm{c}}$ \\ ${ }^{a}$ Department of Economics, Bilkent University, Ankara, Turkey \\ ${ }^{\mathrm{b}}$ Macroeconomic Advisers, LLC, Washington, DC \\ ${ }^{\mathrm{c}}$ Division of Monetary Affairs, Federal Reserve Board \\ Washington, DC
}

We investigate the effects of U.S. monetary policy on asset prices using a high-frequency event-study analysis. We test whether these effects are adequately captured by a single factor - changes in the federal funds rate target - and find that they are not. Instead, we find that two factors are required. These factors have a structural interpretation as a "current federal funds rate target" factor and a "future path of policy" factor, with the latter closely associated with Federal Open Market Committee statements. We measure the effects of these two factors on bond yields and stock prices using a new intraday data set going back to 1990. According to our estimates, both monetary policy actions and statements have important but differing effects on asset prices, with statements having a much greater impact on longer-term Treasury yields.

JEL Codes: E52, E58, E43, G14.

\footnotetext{
*We thank Ben Bernanke, Ken Kuttner, Jon Faust, Jonathan Wright, two anonymous referees, and seminar participants at Bilkent, Koç, and Sabancı Universities, the Central Bank of Turkey, and the Federal Reserve Bank of San Francisco for valuable discussions, comments, and suggestions. Andrea Surratt and Kunal Gullapalli provided excellent research assistance. The views in this paper, and any errors and omissions, should be regarded as those of the authors, and do not necessarily reflect those of the individuals listed above, the Federal Reserve Board, or any other individual within the Federal Reserve System. Author contact: Refet S. Gürkaynak, Division of Monetary Affairs, Federal Reserve Board and Department of Economics, Bilkent University, 06800 Ankara, Turkey (e-mail: refet@bilkent.edu.tr).
} 
The Federal Reserve's announcement following its January 28, 2004, policy meeting led to one of the largest reactions in the Treasury market on record, with two- and five-year yields jumping 20 and 25 basis points (bp) respectively in the half-hour surrounding the announcement - the largest movements around any Federal Open Market Committee (FOMC) announcement over the fourteen years for which we have data. Even more remarkably, this outsized reaction was spurred not by what the FOMC did, but rather by what it said: indeed, the decision to leave the current federal funds rate unchanged was completely anticipated by financial markets, but the FOMC's decision to drop the phrase "policy accommodation can be maintained for a considerable period" from its accompanying statement and replace it with "the Committee believes it can be patient in removing its policy accommodation" was read by financial markets as indicating that the FOMC would begin tightening policy sooner than previously expected. ${ }^{1}$ On this date, then, treating the monetary policy action as a 0 bp surprise change in the current federal funds rate target would be missing the whole story.

In this paper, we investigate the extent to which this observation is true more generally: are the effects of monetary policy announcements on asset prices adequately characterized by a single factor, namely the surprise component of the change in the current federal funds rate target? We perform a test of this hypothesis using the rank test of Cragg and Donald (1997) and strongly reject the hypothesis of a single factor. By contrast, we do not reject the hypothesis that the effects of monetary policy on asset prices are characterized by two factors. By performing a suitable rotation of these unobserved factors, we show that they can be given a structural interpretation as a "current federal funds rate target" factor, corresponding to surprise changes in the current federal funds rate target, and a "future path of policy" factor, corresponding to changes in futures rates out to horizons of one year that are independent of changes in the current funds rate target. We show that this latter ("path") factor has typically been associated with significant changes in FOMC statements, such as the January 28 example above. In this way, we generalize and

\footnotetext{
${ }^{1}$ For example, the front page of The Wall Street Journal reported the following morning that "investors interpreted the omission of 'considerable period' as a signal that the Fed is closer to raising interest rates than many thought" (Ip 2004).
} 
improve the single-factor analysis of the effects of monetary policy on asset prices performed by earlier authors, such as Cook and Hahn (1989), Kuttner (2001), Cochrane and Piazzesi (2002), Rigobon and Sack (2004), Ellingsen and Soderstrom (2003), and Bernanke and Kuttner (forthcoming).

To measure the effects of monetary policy actions and statements on asset prices, we construct a new data set that captures changes in asset prices in a thirty-minute window and in a one-hour window bracketing every FOMC announcement going back to 1990 (we use the term announcement to refer to any means by which a policy decision was communicated to financial markets, including open market operations as well as explicit press releases). The use of intraday data allows us to better isolate the response of asset prices to monetary policy announcements, since we can be almost certain that no other economic news was released within such a brief interval of time. The gains from using intraday data are most apparent in the early 1990s, when on a number of occasions the FOMC eased policy just a few hours after a weak employment report released earlier in the day.

In estimating the separate effects of monetary policy actions and statements, we are not suggesting that FOMC statements represent a policy tool that is completely independent of the federal funds rate target. In particular, FOMC statements likely exert their effects on financial markets through their influence on financial market expectations of future policy actions. Nonetheless, the two-factor approach we employ in this paper greatly adds to our understanding of the response of asset prices to monetary policy announcements - for example, we find that 75 to 90 percent of the explainable variation in five- and ten-year Treasury yields in response to monetary policy announcements is due to the path factor (associated with statements) rather than to changes in the federal funds rate target. We interpret this result as indicating not that policy actions are secondary so much as that their influence comes earlier, when investors build in expectations of those actions in response to FOMC statements (and perhaps other events, such as speeches and testimony by FOMC members).

Our findings have important implications for the conduct of monetary policy in a low-inflation environment. In particular, the fact that FOMC statements have such significant effects on long-term yields suggests that the FOMC may be able to credibly commit to future plans for the federal funds rate. Thus, even when 
faced with a low or zero nominal funds rate, our results indicate that the FOMC may be able to effectively communicate to the markets its intention to keep the federal funds rate low for an extended period, thereby lowering longer-term interest rates and stimulating economic growth. ${ }^{2}$

The remainder of the paper proceeds as follows. Section 1 provides a detailed study of surprises in the federal funds rate target and measures asset price responses to these surprises. Section 2 tests whether there are additional dimensions underlying monetary policy announcements, finds that one additional dimension is required, shows that this additional factor is closely associated with FOMC statements, and estimates the response of asset prices to this additional factor. Section 3 concludes. The appendix provides technical details regarding our factor test and the estimation of the unobserved factors, and a data appendix (only available online at www.ijcb.org) provides a complete listing of our monetary policy announcement dates, times, and federal funds rate and statement surprise measures extending back to 1990 .

\section{The Effects of Changes in the Federal Funds Rate Target on Asset Prices}

\subsection{Methodology}

We begin our analysis in the framework of one-dimensional measures of monetary policy surprises that has been used in the existing literature. To measure the effects of unexpected monetary policy actions (changes in the federal funds rate) on asset prices, we rely on the following regression, which has been frequently estimated in the literature:

$$
\Delta y_{\mathrm{t}}=\alpha+\beta \Delta x_{t}+\varepsilon_{t}
$$

where $\Delta x_{t}$ denotes the surprise component of the change in the federal funds rate target announced by the FOMC, $\Delta y_{t}$ denotes the change in a bond yield or stock market index over an interval that

\footnotetext{
${ }^{2}$ Reifschneider and Williams (2000) and Eggertsson and Woodford (2003) provide theoretical support for the argument that a central bank is relatively unconstrained by the zero nominal bound so long as it can credibly commit to future policy actions. Bernanke, Reinhart, and Sack (2004) investigate the potential effectiveness of monetary policy at the zero nominal bound empirically.
} 
brackets the monetary policy announcement, and $\varepsilon_{t}$ is a stochastic error term that captures the effects of other factors that influence the asset in question.

We use a high-frequency event-study analysis to estimate equation (1). One generally cannot estimate equation (1) using monthly or quarterly data due to simultaneous equations and omitted variables bias. In particular, the change in monetary policy could actually be a response of monetary policy to the change in the asset price that took place earlier in the month or quarter, due to the direct effects of stock market wealth on the economic outlook or due to the signal that term spreads provide about future economic activity and inflation. ${ }^{3}$ Alternatively, both the change in monetary policy and the change in the asset price could be responding to important macroeconomic news (captured by $\varepsilon_{t}$ ) that was released earlier in the period, such as an employment report. ${ }^{4}$ In either case, the classical regression assumption that $\varepsilon_{t}$ is orthogonal to $\Delta x_{t}$ is violated. ${ }^{5}$

These problems can be mitigated by using higher-frequency data to shrink the time period around the policy decision. Kuttner (2001), for example, uses daily data to measure changes in Treasury yields and the surprise component of FOMC monetary policy announcements. Cochrane and Piazzesi (2002) and Ellingsen and

\footnotetext{
${ }^{3}$ Rigobon and Sack (2003) discuss reasons why asset prices might be expected to feed back into monetary policy. Using a heteroskedasticity-based identification procedure, they estimate a statistically and economically significant response of monetary policy to the stock market, and this response has the expected positive sign. Using their heteroskedasticity-based procedure, Rigobon and Sack (2004) also estimate the size of the endogeneity and omitted variables problems in estimating equation (1).

${ }^{4}$ Asset prices can respond to macroeconomic news for many reasons other than changes in monetary policy expectations: First, information about economic output is likely to influence expectations of corporate earnings and dividends, hence stock prices; second, information about the government budget or current account deficit would, assuming home bias in savings and imperfect Ricardian equivalence, affect bond yields; third, investors' appetite for risk can change in response to economic developments, to name a few examples.

${ }^{5}$ One way to partially account for these issues is to estimate a VAR for the asset price, the policy instrument, and other relevant macroeconomic variables, as in Leeper, Sims, and Zha (1996) and Evans and Marshall (1998). The problem with this approach is that the recursive identifying restrictions typically employed are not plausible for fast-moving financial market variables. (Two exceptions to this rule are the heteroskedasticity-based identification procedure used by Rigobon and Sack [2003, 2004] and the high-frequency identification procedure used by Cochrane and Piazzesi [2002] and Faust, Swanson, and Wright [2004a].)
} 
Soderstrom (2003) perform variations on this analysis, and Bernanke and Kuttner (forthcoming) apply the method to measure the effects of monetary policy announcements on the stock market. However, as noted by Rudebusch (1998) and Bernanke and Kuttner (forthcoming), simultaneity in equation (1) is still a potential problem even at daily frequency because, for a time, the FOMC often changed its target for the federal funds rate just hours after (and in response to) the Bureau of Labor Statistics' employment report release. As a result, event-study regressions using daily data in part capture the endogenous response of asset prices and monetary policy to the information that was released earlier in the day, as well as noise from other financial market developments that took place throughout the day.

We address this potential problem by estimating regression (1) using intraday data to measure both the funds rate surprise $\Delta x_{t}$ and the change in the asset price $\Delta y_{t}$. By measuring these changes in a sufficiently narrow window of time around the monetary policy announcement, we can be sure that the FOMC decision was in no way influenced by asset price movements or other macroeconomic news over that interval. In addition, by shrinking the event-study window down to an hour or less, it becomes much less likely that any other significant events took place within this narrow window that might have influenced asset prices, thereby increasing the precision of our estimates.

\subsection{Dates and Times of Monetary Policy Announcements}

To perform the above analysis using intraday data, we first put together a complete list of dates and times of monetary policy announcements from January 1990 through December 2004. In February 1994, the FOMC began issuing a press release after every meeting and every change in policy, and thus the announcement dates and times are simply those of the corresponding press releases. ${ }^{6}$ Prior to 1994, the FOMC did not explicitly announce changes in its target for the federal funds rate, but such changes were implicitly

\footnotetext{
${ }^{6}$ Since 1995 , these press releases have occurred at about 2:15 p.m., after regularly scheduled FOMC meetings; press releases for intermeeting policy moves and FOMC decisions in 1994 were released at varying times throughout the day. We obtained all of these dates and times from the office of the secretary of the Federal Reserve Board.
} 
communicated to financial markets through the size and type of open market operation. Thus, prior to 1994, the date and time of a monetary policy announcement are typically those of the next open market operation following the FOMC decision. ${ }^{7}$

The dates, times, and methods of communication of FOMC monetary policy announcements are reported in table 1 of the online data appendix. Note that this listing includes not just dates on which the FOMC actually changed the federal funds rate, but also dates on which there was an FOMC meeting followed by no change in policy, since in some cases the FOMC's decision not to change policy surprised financial markets and led to movements in asset prices. The rightmost column of this table reports other major macroeconomic data releases that took place on each date, before the monetary policy announcement. From the table, we can see that eight monetary policy announcements occurred on the date of an employment report release, seven announcements occurred on the date of a gross domestic product release, nine occurred on the date of a consumer price index release, and five on the date of a producer price index release, to name just a few.

\subsection{The Surprise Component of Federal Funds Rate Changes}

For each monetary policy announcement, we measure the surprise component of the change in the federal funds rate target using federal funds futures. We use the surprise component of monetary policy announcements in estimating regression (1) because changes in policy that are expected by financial markets should have little or

\footnotetext{
${ }^{7}$ On a few occasions between 1990 and 1994, the FOMC issued, prior to the open market operation, a press release announcing a change in the discount rate offered to depository institutions, and market participants correctly inferred from the press release a corresponding change in the target federal funds rate as well. On those occasions, we set the time of the monetary policy announcement to the time of the discount rate change press release. Open market operations over this period were conducted at 11:30 a.m. every day. There are a few dates on which volatility in the federal funds market prevented the Open Market Trading Desk from successfully communicating the FOMC's intentions for the funds rate the first morning after the FOMC's decision (see Kuttner 2003). On these dates, we regard the announcement as having taken place on whichever morning the Credit Markets column of The Wall Street Journal regarded as a clear signal of the Federal Reserve's intentions, as reported by Kuttner (2003). This is more of an issue prior to 1990 than for our sample period in this paper.
} 
no effect on asset prices, a hypothesis that is confirmed by Kuttner (2001). Thus, using the raw changes in the federal funds rate target as the right-hand-side variable $\Delta x_{t}$ would impart an errors-in-variables bias to our estimates of $\beta$ to the extent that the monetary policy decisions were correctly anticipated by financial markets.

Federal funds futures have traded at the Chicago Board of Trade exchange since October 1988 and settle based on the average effective federal funds rate that is realized for the calendar month specified in the contract. Thus, daily changes in the current-month futures rate largely reflect revisions to the market's expectations for the federal funds rate over the remainder of the month. As described in the appendix, the change in the current month's contract rate on the day of an FOMC announcement can be scaled up to account for the timing of the announcement within the month, and thereby measure the surprise component of the FOMC's announcement for the federal funds rate. For the present paper, we acquired tick-by-tick data on all federal funds futures contract trades from January 1990 to the present from Genesis Financial Technologies. To provide a sense of the quality of this data and its advantages, figure 1 graphs the data on three illustrative dates:

1. June 25, 2003, was the date of a regularly scheduled FOMC meeting (see panel a). Trades were intermittent throughout the day until just before and just after the FOMC's press release at 2:15 p.m. At that time, the FOMC announced that it was lowering its target for the federal funds rate from 1.25 percent to 1 percent. According to surveys and press reports both before and after the policy announcement, many market participants had been expecting the FOMC to ease policy by $50 \mathrm{bp}$ at the meeting. Thus, this decision is characterized as a $13 \mathrm{bp}$ tightening surprise under our measure. This example illustrates two key points: First, financial markets seem to fully adjust to the policy action within just a few minutes - i.e., there is no evidence of learning or sluggish adjustment to the target rate decision going on after about 2:20 p.m. in this example. Second, the federal funds rate surprise is not necessarily in the same direction as the federal funds rate action itself.

2. April 9, 1992, was the date of an intermeeting monetary policy move (see panel b). The FOMC reduced its target for the federal funds rate from 4 percent to 3.75 percent that morning, but given that this date precedes 1994, the FOMC did not issue a press release 


\section{Figure 1. Intraday Trading in Federal Funds Futures Contracts}

(a) June 25, 2003 (July 2003 Contract)

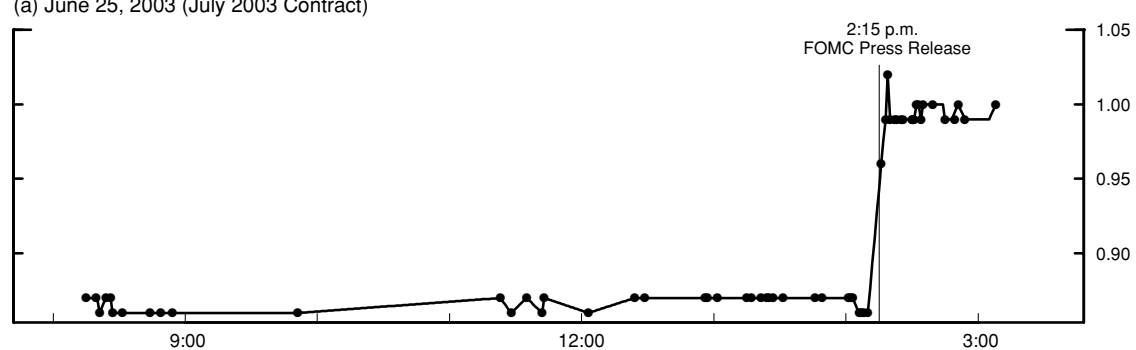

(b) April 9, 1992 (April 1992 Contract)

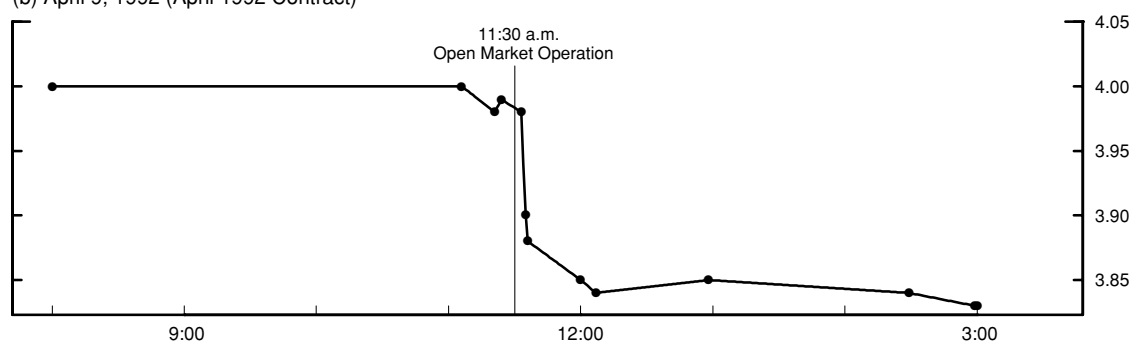

(c) September 4, 1992 (September 1992 Contract)

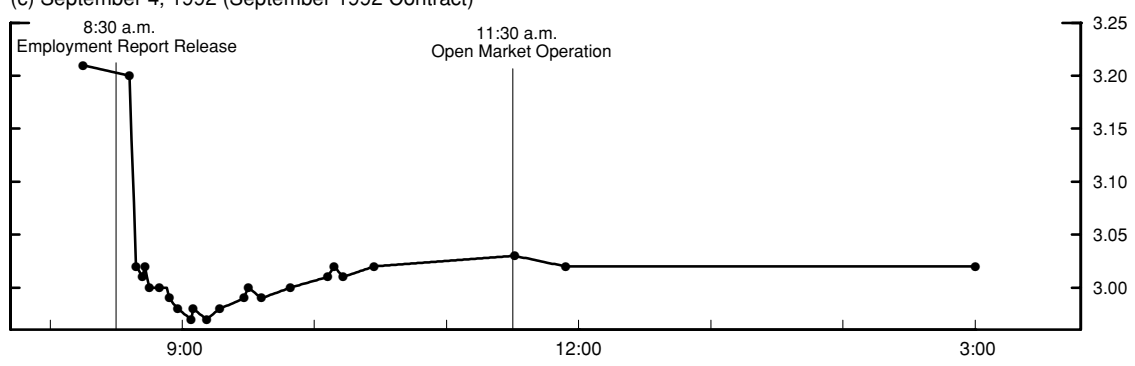

about its change in policy to the public. As can be seen in the figure, trading in federal funds futures was thin until shortly before the open market operation at 11:30 a.m. At that time, the Open Market Trading Desk injected a significant quantity of reserves into the market, and market participants correctly inferred from this that the FOMC had changed its target for the funds rate, causing the futures rate to move quickly to the new target rate. ${ }^{8}$

\footnotetext{
${ }^{8}$ The federal funds futures contract rate falls to 3.85 percent after the announcement rather than the new funds rate target of 3.75 percent because nine
} 
3. September 4, 1992, witnessed the release of a very weak employment report at 8:30 a.m. (see panel c). In response to that report, investors significantly revised downward their expectations for the federal funds rate, pushing the futures rate down sharply. Sometime after the poor data release, the FOMC decided to reduce its target for the federal funds rate from 3.25 percent to 3 percent. Again, because there was no press release, the FOMC's decision became known to the markets at 11:30 a.m., the time of the open market operation. In contrast to panel b, however, the FOMC's decision for the funds rate on this date was essentially completely anticipated by the time it was signaled to the market - indeed, our intraday measure of the funds rate surprise (reported in table 2 of the online data appendix and discussed below) is $0 \mathrm{bp}$. By contrast, the daily measure of the funds rate surprise is $-22 \mathrm{bp}$, because it incorporates the endogenous policy response to the weak employment report. In this case, we would not want to use the daily measure of the funds rate surprise in an event-study regression, because it would suffer from the omitted variables problem discussed earlier (in that the employment report itself has sizable effects on stock prices, bond yields, and monetary policy expectations).

To focus on the monetary policy decision itself, we compute policy surprises by looking at changes in the futures rate in narrow windows around the FOMC announcements. More specifically, online data appendix table 2 reports two intraday measures, a "tight" window and a "wide" window, which begin ten (fifteen) minutes prior to the monetary policy announcement and end twenty (forty-five) minutes after the policy announcement, respectively, for the period from January 1990 through December $2004 .^{9}$ For comparison, the table also reports a "daily" window that begins with the financial market close the day before the policy announcement and ends with the financial market close the day of the policy announcement. On most of the days in our sample, the two intraday measures are quite

days of the month have already elapsed with an average federal funds rate of 4 percent, which will result in a month-average funds rate for April of 3.85 percent.

${ }^{9}$ When there is no federal funds futures trade exactly at the beginning of the specified window, we use the most recent price. When there is no trade exactly at the end of the specified window, we use the next available trade price. Federal funds futures trading is often sparse early in our sample period, but becomes significantly more dense around the times of macroeconomic data releases and monetary policy announcements. 
similar to the daily measure: the average absolute difference between the daily and two intraday surprise measures is only about $2 \mathrm{bp}$, and the difference is $0 \mathrm{bp}$ on many days. There are a few days, however, on which the differences between the intraday measures and the daily measure are quite large: for example, there are five observations for which the discrepancy between the tight surprise and the daily surprise exceeds $10 \mathrm{bp}$. Each of those observations took place before 1994 on the day of an employment report release, as in the example of September 4, 1992, discussed previously. Figure 2 makes this point graphically: as can be seen in the top panel, the tight window

Figure 2. Measures of Surprises in the Federal Funds Rate Target
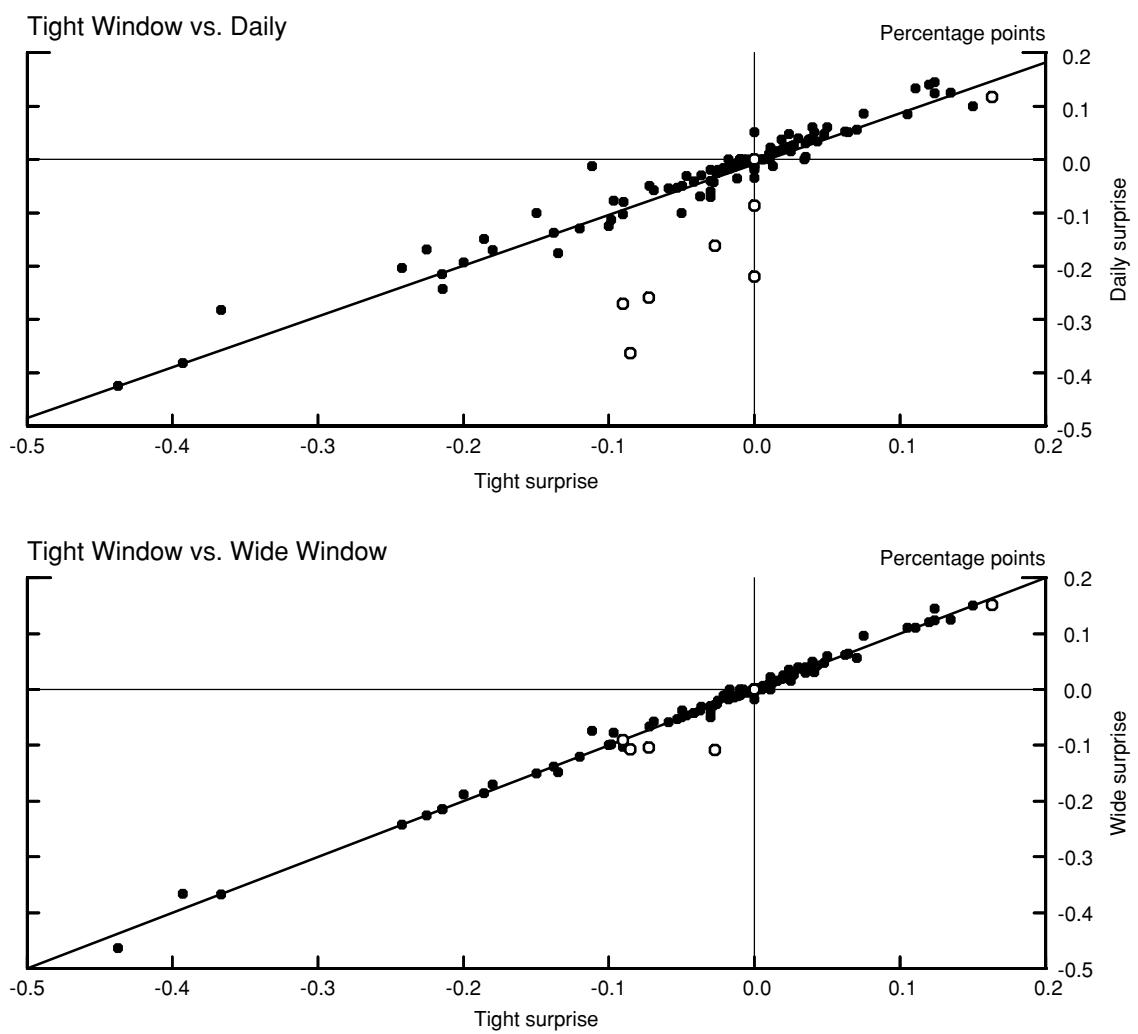

Note: Hollow circles denote days of employment report releases. 
and daily window surprises are in very close agreement on all but a handful of dates, almost all of which correspond to days on which the FOMC was responding to an employment report release (depicted by the hollow circles). By contrast, in the bottom panel of the figure, we see that the two intraday measures are in very close agreement on all dates in our sample.

We draw two conclusions from these observations. First, the FOMC decision accounted for the vast majority of the movement in the federal funds futures rate on all of the non-employment-report days in our sample. This is perhaps surprising, given the large number of other data releases that also coincided with monetary policy announcements in data appendix table 1 , and is in itself an important finding: it shows that for samples that exclude employment report dates, or samples that begin in 1994, the surprise component of monetary policy announcements can be measured very well using just daily data. Second, FOMC actions were priced into the federal funds futures market almost immediately - quickly enough to be completely captured by our tight, thirty-minute window-consistent with the examples discussed above. Thus, we can feel comfortable focusing on the analysis using our tight window of thirty minutes, although we will report results using the wider one-hour window as well.

\subsection{The Effect of Federal Funds Rate Changes on Asset Prices}

Table 1 presents our results for regression equation (1) estimated using intraday data on bond yields and stock prices. ${ }^{10}$ The independent variable is the surprise component of the change in the federal funds rate target just described, and the dependent variable is the change in the financial variable measured over the same window. We present results for the tight (thirty-minute), wide (one-hour), and daily windows described above.

Our results for stock prices imply that, on average, a surprise 25 bp tightening in the federal funds rate leads to a little more than

\footnotetext{
${ }^{10}$ We obtained tick-by-tick Treasury yield data back to June 1991 for on-therun Treasury securities from GovPX, a consortium of interdealer brokers that accounted for a large portion of trading volume in Treasury securities over our sample. For equity prices, we obtained five-minute intraday quotes on the S\&P 500 index back to the mid-1980s, which are available from a variety of sources.
} 


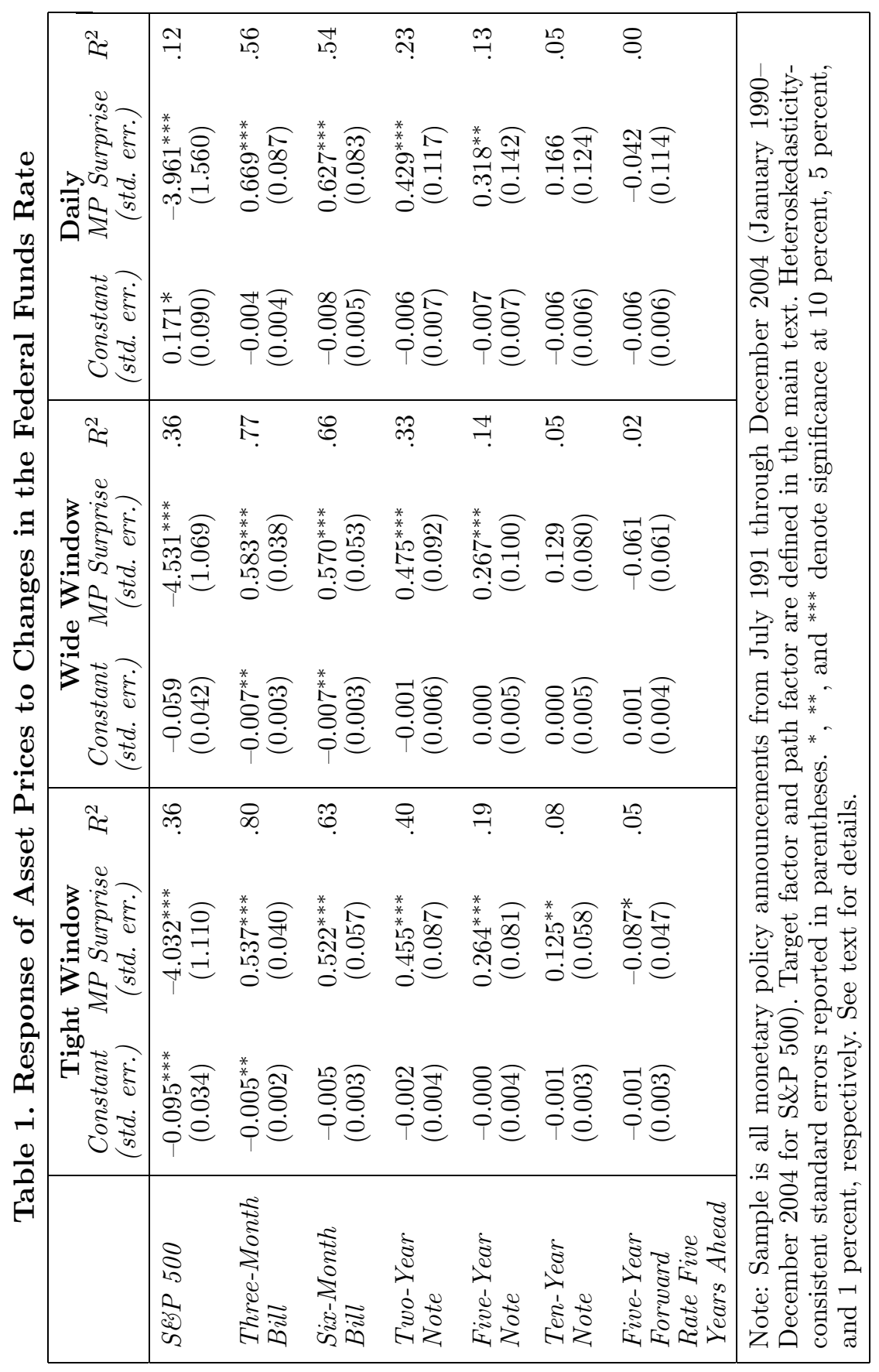


a 1 percent fall in the $\mathrm{S} \& \mathrm{P} 500$, and these estimates are highly significant. The estimated coefficients do not differ greatly across the intraday and daily regressions, although the effects of the omitted employment report variable can be seen clearly in the scatter plots in figure 3: the handful of days on which the policy decision followed an employment report, shown by the hollow points, do not appear unusual when the intraday data are used, but in the daily data they stand out as large policy easings that yielded no gains in equity prices, most likely due to the negative direct influence of the weak employment reports.

The most striking feature of figure 3 , however, is the increase in tightness of the relationship as we move from daily to intraday data. By eliminating the effects of employment reports and other news that occurred on the days of monetary policy announcements, the relationship between monetary policy actions and equity prices becomes much clearer in the figure. This advantage also stands out in the regression results in table 1 , in terms of the much greater precision of the coefficient estimates and a tripling of $R^{2}$ from .12 to .36 .

Intraday data yield additional benefits for our Treasury yield regressions. As shown in figure 4, employment report days (the hollow points) stand out in the daily data as very large funds rate surprises and large changes in the three-month Treasury-bill rate in the same direction, reflecting the fact that the employment report has a very large influence on both the FOMC decision and the short end of the Treasury yield curve. ${ }^{11}$ By contrast, those days do not stand out at all when the intraday windows are used. Moreover, employment report surprises appear to have a larger effect on the T-bill rate compared to policy surprises. Because of this, the estimated coefficient in the regression is biased upward if daily data are used. As with equity prices, the response of the T-bill rate to monetary policy actions is also estimated much more precisely using intraday data, reflected in the much smaller standard errors (about half the size of the daily measures) and the much higher $R^{2}$ (.80 versus .56).

The differences in the coefficients between the intraday regressions and the daily regression become much smaller at horizons of

\footnotetext{
${ }^{11}$ Recall that our intraday Treasury data extend back only to June 1991, so our Treasury yield regressions and graphs contain eighteen fewer observations (and only five employment report dates instead of eight).
} 
Figure 3. Response of S\&P 500 to Monetary Policy Surprises
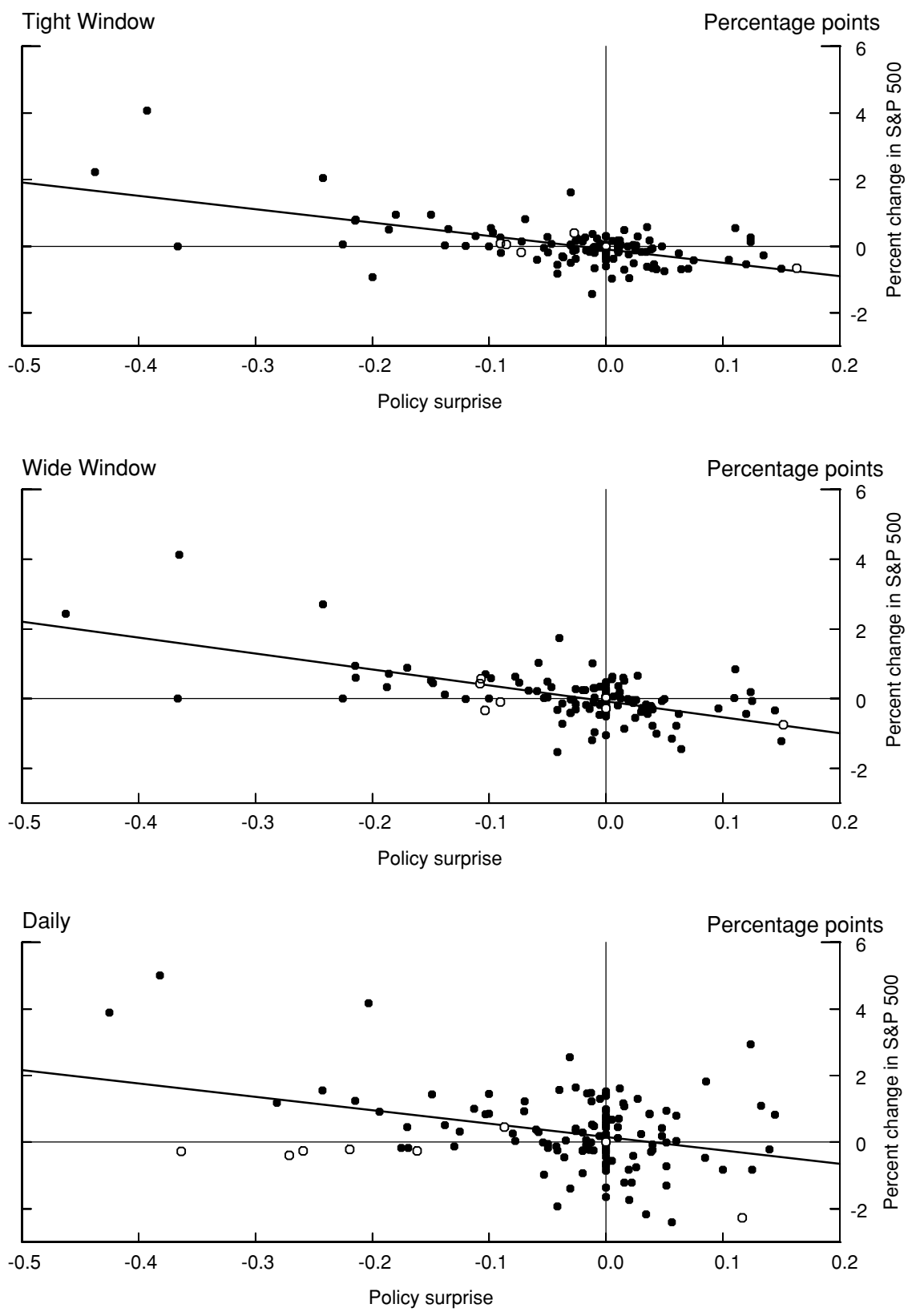

Note: Hollow circles denote days of employment report releases. 
Figure 4. Response of Three-Month Treasury Yield to Monetary Policy Surprises
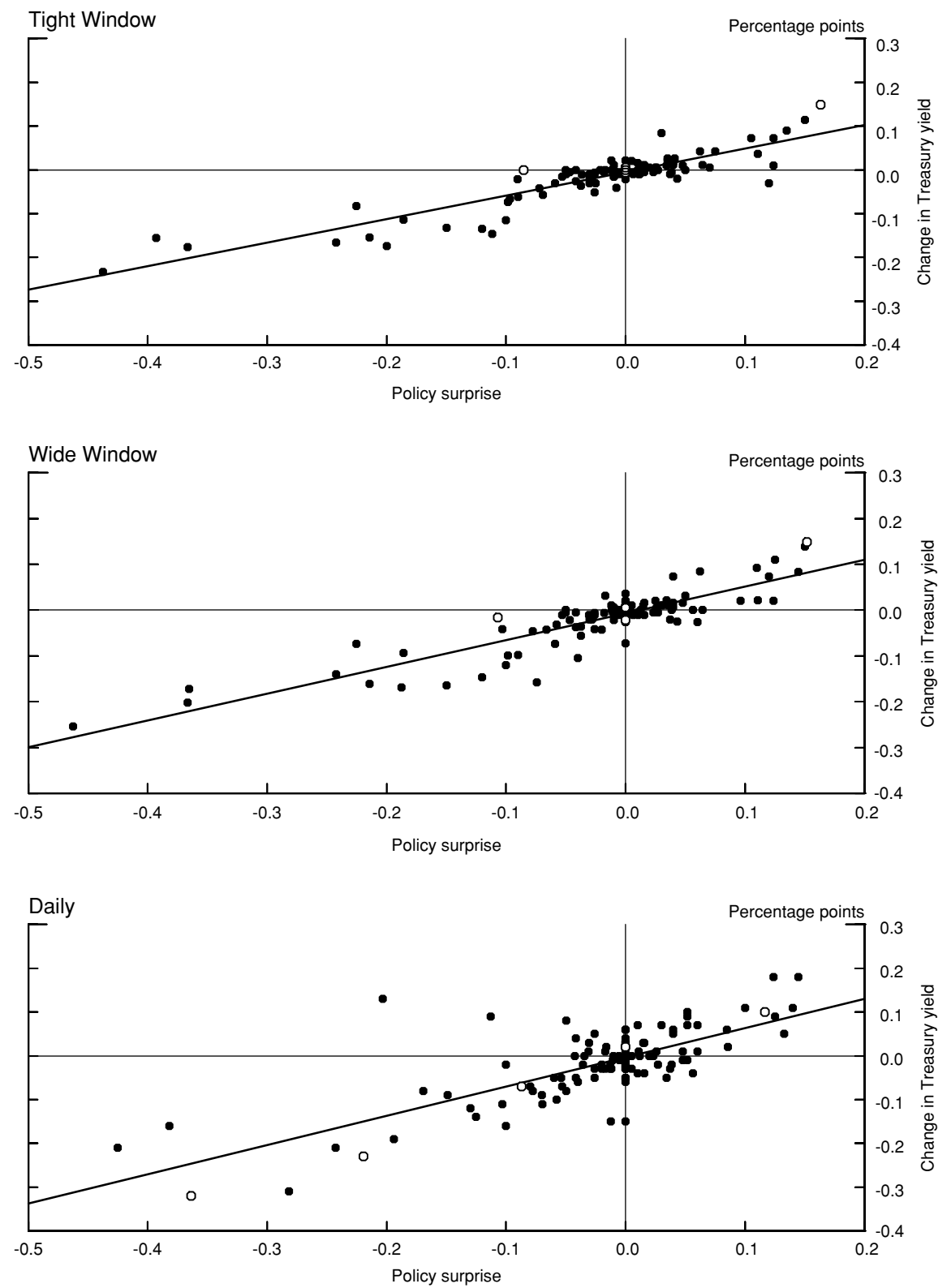

Note: Hollow circles denote days of employment report releases. 
two years or more, but this observation is somewhat misleading, as a single outlier, January 3,2001 , pulls the daily estimate toward the intraday one (shown in figure 5). ${ }^{12}$ Without that one observation in the upper left, the daily regression would estimate a significant response of the ten-year rate to the FOMC announcement of 0.28 rather than the statistically insignificant 0.17 that is estimated including the outlier. By contrast, using the intraday data, the estimated coefficient changes only very slightly (from 0.13 to 0.17 ) when we exclude that observation. As before, the precision of our estimates also improves dramatically using intraday data, with the standard errors being about half as large. This makes the response of the ten-year Treasury yield - which is statistically indistinguishable from zero using daily data - significantly greater than zero (albeit small) using our tight-window data.

The response of the term structure can also be expressed in terms of forward rates. We compute the five-year forward Treasury rate beginning five years ahead from five- and ten-year Treasury yields using the Shiller-Campbell-Schoenholtz (1983) approximation. The estimated response of the forward rate to the policy surprise is negative over this sample. This is consistent with the findings of Gürkaynak, Sack, and Swanson (2003) that far-ahead forward rates typically move inversely with the monetary policy surprise, although our estimates here are not highly statistically significant, partly because we cannot compute intraday forward rate changes that begin more than five years ahead. Gürkaynak, Sack, and Swanson (2003) present their findings in terms of the nine-year-ahead one-year forward rate, which is probably a better measure of far-ahead forward rates. ${ }^{13}$

\footnotetext{
${ }^{12}$ On that day, although the FOMC unexpectedly eased policy, which would normally be associated with a fall in Treasury yields, market participants reportedly became much more optimistic about the economic outlook as a result, leading to a huge rally in equity markets (including an astounding 14 percent rise in the NASDAQ that afternoon) and a large upward shift in Treasury yields. This outlier poses particular problems for a researcher using only daily data, since it is unclear whether the observation should be dropped or retained, and the empirical results are highly sensitive to this choice; by contrast, using the intraday data, the observation poses no problems.

${ }^{13}$ We only have intraday data for the on-the-run five- and ten-year Treasury notes, which gives us the forward rate from five to ten years ahead, but not for any finer subintervals. The five-year-ahead five-year rate may not capture movements in far-ahead forward rates as well as the nine-year-ahead one-year rate.
} 
Figure 5. Response of Ten-Year Treasury Yield to Monetary Policy Surprises
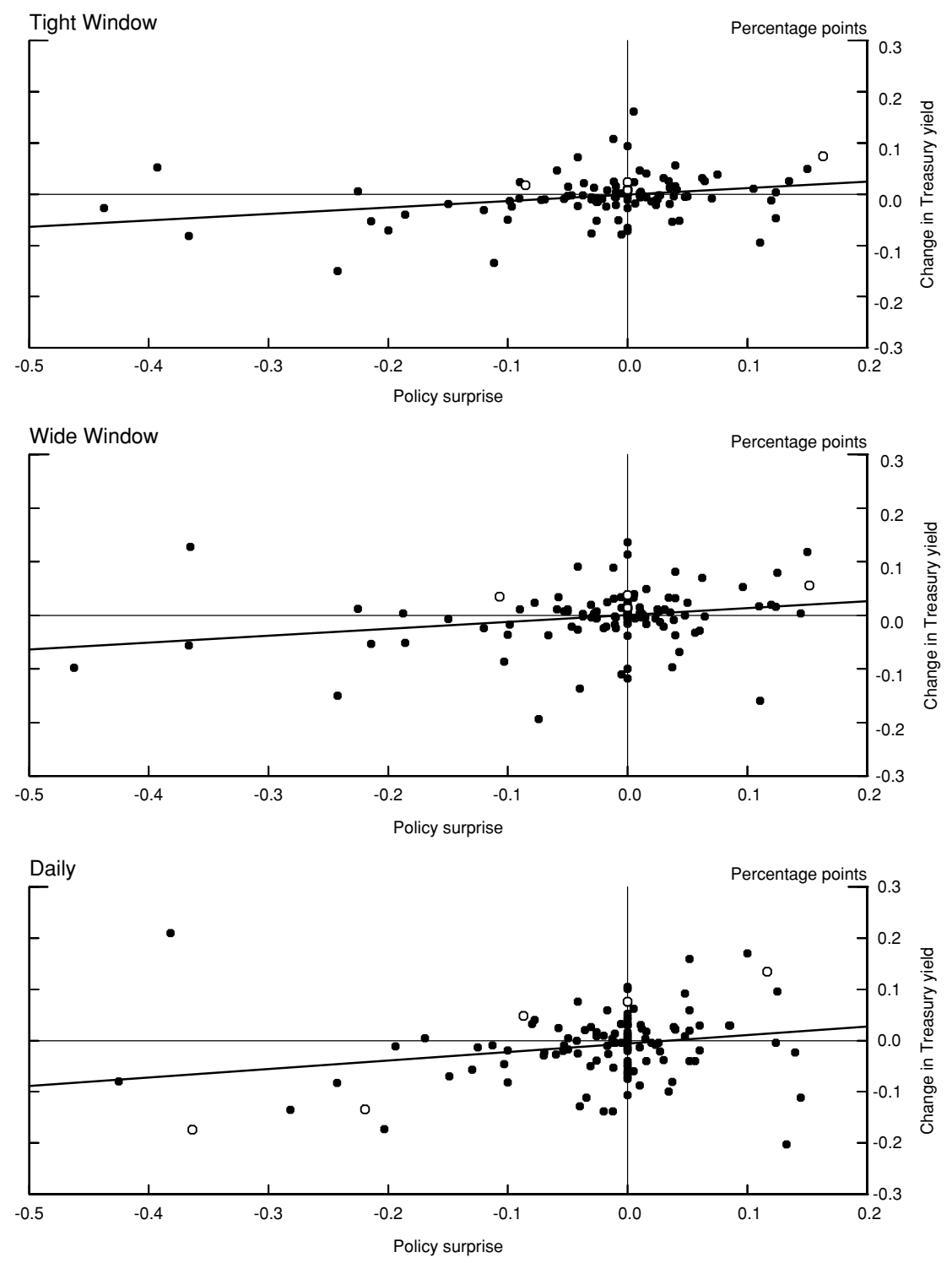

Note: Hollow circles denote days of employment report releases. 


\section{The Effects of FOMC Statements on Asset Prices}

\subsection{Testing for Additional Dimensions of Monetary Policy Announcements}

The preceding section assumed that the effects of FOMC announcements on asset prices are completely (or at least adequately) described by the surprise component of the change in the federal funds rate target. Although this assumption is standard in the existing literature, the example of January 28,2004 , given earlier raises serious questions regarding its validity. In this section, we ask whether the example of January 28 was a one-time occurrence or a manifestation of something much more systematic. If the latter, how many additional dimensions are required to adequately characterize monetary policy announcements? ${ }^{14}$

The above questions essentially ask how many latent factors underlie the response of asset prices to monetary policy announcements. Let $X$ denote the $T \times n$ matrix, with rows corresponding to monetary policy announcements, columns corresponding to asset prices, and each element of $X$ reporting the change in the corresponding asset price in a thirty-minute window around the corresponding announcement. Writing $X$ in the form

$$
X=F \Lambda+\eta
$$

where $F$ is a $T \times k$ matrix of unobserved factors (with $k<n$ ), $\Lambda$ is a $k \times n$ matrix of factor loadings, and $\eta$ is a $T \times n$ matrix of white noise disturbances, we wish to know how many factors (columns of $F$ ) are required to adequately describe $X$. The hypothesis that a single factor (for example, the surprise component of changes in the federal funds rate) is sufficient is a statement that there exists a $T \times 1$ vector $F$ and constants $\lambda_{i}, i=1, \ldots, \mathrm{k}$, such that the matrix $X$ is described by $F \times\left[\lambda_{1}, \ldots, \lambda_{k}\right]$ up to white noise.

This restriction on the structure of the data $X$ can be tested using the matrix rank test of Cragg and Donald (1997). In brief, the null hypothesis that $X$ is described by $k_{0}$ common factors can

\footnotetext{
${ }^{14}$ One can imagine that several dimensions might be required, corresponding to information about the future path of interest rates, policymakers' objectives and preferences, and perhaps the future paths of output and inflation, if the FOMC possesses private information about these latter two variables.
} 
be tested against the alternative that $X$ is described by $k>k_{0}$ factors by measuring the minimum distance between $\operatorname{Cov}(X)$ and the covariance matrices of all possible factor models (2) with $k_{0}$ factors. This distance, after a suitable normalization, has a limiting $\chi^{2}$ distribution with $\left(n-k_{0}\right)\left(n-k_{0}+1\right) / 2-n$ degrees of freedom. Additional details of the method are provided in the appendix.

Table 2 reports the results of this test applied to two sets of assets: one that includes all of our Treasury yields and stock prices, and another that includes only federal funds futures and eurodollar futures with one year or less to expiration. ${ }^{15}$ We consider the latter set of assets in this table because they will turn out to be very useful in the structural interpretation of the factors, below.

As can be seen in table 2, the hypothesis that the response of asset prices to monetary policy announcements is characterized by zero or by one common factor is clearly rejected. An important and direct corollary of this finding is that surprise changes in the federal funds rate alone are not sufficient to describe the response of asset prices to monetary policy announcements, in contrast to one of the standard assumptions in the literature. However, as is also clear in table 2, we find that two factors are sufficient - tests of this hypothesis are not rejected at even the 10 percent level. Given our strong rejection of zero or one factor, this result is perhaps somewhat surprising - it implies that, despite the potentially unlimited complexity of monetary policy statements and hence announcements, financial markets nonetheless have reacted as if there is essentially only one additional degree of information beyond the surprise change in the federal funds rate target. In the remainder of this section, we turn to estimating and interpreting this additional dimension of U.S. monetary policy and estimating its effect on Treasury yields and stock prices.

\footnotetext{
${ }^{15}$ Treasury yields include the three-month, six-month, two-year, five-year, and ten-year yields. Recall that we only have intraday data for these yields beginning in July 1991, which explains the smaller number of observations for these securities in table 2. For futures rates, we use five contracts that pin down the expected path of the federal funds rate over the next year without overlapping: the current-month and three-month-ahead federal funds futures contracts (with a scale factor to account for the timing of FOMC meetings within the month) and the two-, three-, and four-quarter-ahead eurodollar futures contracts. See the appendix for details. Avoiding overlap is desirable because very similar assets will tend to covary strongly, producing an additional factor even if that variation is orthogonal to all of the other assets in $X$.
} 


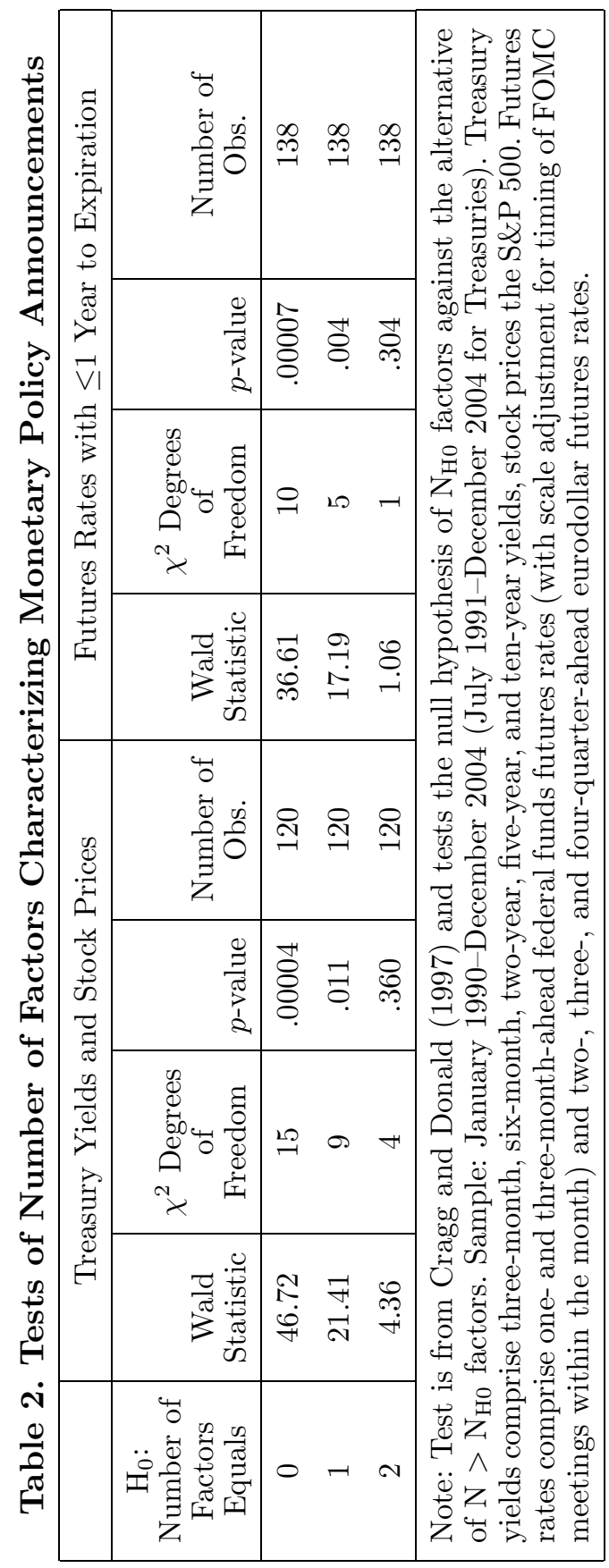




\subsection{Estimation of the Two Factors}

We estimate the unobserved factor matrix $F$ using the standard method of principal components applied to our data matrix $X .{ }^{16}$ This procedure decomposes the matrix $X$ into a set of orthogonal vectors $F_{i}, i=1, \ldots, n$, where $F_{1}$ is the (length- $T$ ) vector that has maximum explanatory power for $X, F_{2}$ is the vector that has maximum explanatory power for the residuals of $X$ after projecting each column on $F_{1}$, and so on. Based on the results of our factor rank test, above, we will restrict attention to the first two factors $\left(F_{1}\right.$ and $F_{2}$ ) estimated by this procedure. Details are provided in the appendix.

As mentioned above, we estimate the unobserved factors $F_{1}$ and $F_{2}$ using the set of federal funds futures and eurodollar futures rates with one year or less to expiration that characterize the expected path of the funds rate over the upcoming year. ${ }^{17}$ Estimates of the unobserved factors using Treasury yields and stock prices are quite similar; the reason for focusing on the shorter-term futures rates for estimation is that it makes the structural interpretation of the two factors, and interpretation of the effects of the two factors on bond yields and stock prices, more clear.

\subsection{A Structural Interpretation of the Two Factors}

The two factors $F_{1}$ and $F_{2}$ explain a maximal fraction of the variance of $X$, but do not have a structural interpretation. For example, both factors are correlated with the surprises in the current federal funds rate target, so we cannot interpret one factor as the change in the federal funds rate target and the other factor as some other dimension of monetary policy. To address this deficiency and allow for a more structural interpretation of the factors, we perform a rotation of $F_{1}$ and $F_{2}$ to yield two new factors, which we call $Z_{1}$ and

\footnotetext{
${ }^{16}$ The primary alternative to principal components is Kalman filtering, which is optimal under the assumption of normally distributed residuals. However, the normality assumption may not fit our data very well.

${ }^{17}$ Gürkaynak, Sack, and Swanson (2002) show that these rates are the best financial market predictors of the federal funds rate at horizons out to a year. As one familiar with factor decompositions of the yield curve might expect, we find that $F_{1}$ and $F_{2}$ look very much like "level" and "slope" factors from that literature, although our sample differs from that literature in that we focus exclusively on the brief intervals around monetary policy announcements.
} 
$Z_{2}$, which are still orthogonal and explain the matrix $X$ to exactly the same extent that $F_{1}$ and $F_{2}$ did, but for which the second factor $\left(Z_{2}\right)$ has no effect on the current federal funds rate. In other words, we define

$$
Z=F U
$$

in such a way that $U$ is a $2 \times 2$ orthogonal matrix and the second column of $Z$ is a vector that is associated on average with no change in the current-month federal funds futures rate. Exact details of this rotation are reported in the appendix. As a result of this transformation, we can regard the unexpected change in the current target for the federal funds rate as being driven exclusively by $Z_{1}$ (plus a small amount of white noise), and $Z_{2}$ represents all other aspects of FOMC announcements that move futures rates for the upcoming year without changing the current federal funds rate. The factor $Z_{2}$ therefore includes any information (besides the decision for the current target rate) that affects the expected path for monetary policy over the upcoming year. Accordingly, we refer to $Z_{1}$ and $Z_{2}$ as the "target" factor and the "path" factor, respectively. The estimated values for the target and path factors for each monetary policy announcement in our sample are reported in table 3 of the online data appendix.

Note that the target factor $\left(Z_{1}\right)$ defined in this way should be similar to - but not exactly equal to - the measure of federal funds target surprises we presented in the previous section and reported in data appendix table $2{ }^{18}$ To check the tightness of the relationship between these two measures, we regressed our target surprises on the factor $Z_{1}$ (results not reported) and found that $Z_{1}$ is in fact very close to our previous measure, with a correlation of over 95 percent $\left(R^{2}\right.$ of .91). Thus, to further facilitate interpretation of $Z_{1}$

\footnotetext{
${ }^{18}$ The two measures generally are not identical because the factor estimation procedure strips out white noise from the data. Thus, $Z_{1}$ will tend to exclude part of the "timing" component of federal funds rate surprises-i.e., changes in the funds rate target that are only a surprise to the extent that they occur at the present meeting instead of the next meeting. (Gürkaynak, Sack, and Swanson [2002] and Gürkaynak [2005] discuss "timing" surprises in more detail.) To the extent that assets other than the current-month federal funds futures rate ignore these timing surprises, the factor estimation procedure will assign this component to white noise rather than to $Z_{1}$. In this respect, $Z_{1}$ is a better measure of the important component of funds rate surprises than is the standard measure based on the current-month futures rate.
} 
as the surprise change in the funds rate target, we normalize its scale so that a change of .01 in $Z_{1}$ corresponds to a surprise of $1 \mathrm{bp}$ in the federal funds rate target. Similarly, to facilitate interpretation of the second factor, we normalize its scale so that the effect of $Z_{2}$ on the four-quarter-ahead eurodollar futures rate is exactly the same as the effect of $Z_{1}$ on the four-quarter-ahead eurodollar futures rate, about 55 bp. ${ }^{19}$

\subsection{The Association Between the Path Factor and FOMC Statements}

The path factor $Z_{2}$ corresponds to all aspects of FOMC announcements that move futures rates for the upcoming year without changing the current federal funds rate; thus, it is to some extent a residual that is subject to various interpretations. In this section, we present three pieces of evidence that show a close correlation between the path factor and FOMC statements: first, a time series plot that allows comparison of pre-1994 to post-1994 (and also statement to nonstatement) monetary policy announcements; second, a regression test of the path factor on a dummy variable indicating the presence of an FOMC statement; and third, a case study of the largest path factor observations in our sample. In addition, in section 2.5 below, we compare our estimated effects of the path factor on asset prices to the effects of the FOMC minutes release on January 4, 2005, which, because of new procedures adopted by the FOMC, has many of the features of an FOMC statement release with no change in the funds rate target.

In figure 6 , we plot the target and the path factors over time, with dates on which there was an FOMC statement plotted as solid bars and those on which there was no FOMC statement (dates prior to 1994 and dates from 1994 to 1999 on which there was no change in the federal funds rate target) plotted as hollow bars. As can be seen in the figure, there have been many large realizations of the path factor in recent years, while realizations of the path factor prior to 1994 (and on nonstatement days in general) were typically very small.

\footnotetext{
${ }^{19}$ These scale normalizations are performed for the July 1991-December 2004 sample, the period for which we have data on U.S. Treasury yields.
} 
Figure 6. Monetary Policy Surprises as Two Factors
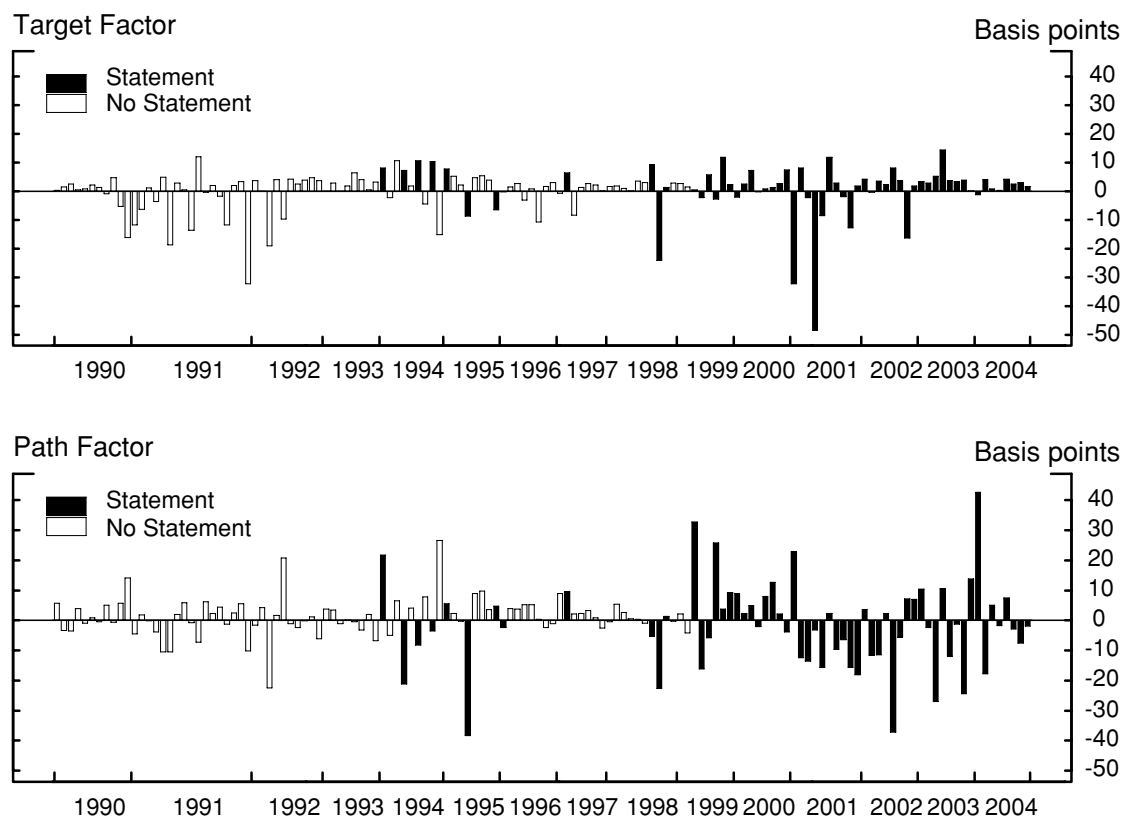

Table 3 verifies this observation econometrically by regressing the absolute value of the path factor on a constant and a dummy variable that takes on the value one for all dates on which there was an FOMC statement. The coefficient on the dummy variable is positive and highly statistically significant, allowing us to strongly

Table 3. Estimated Effects of Policy Statements on the Size of the Path Factor

\begin{tabular}{|c|c|c|c|c|}
\hline $\begin{array}{c}\text { Dependent } \\
\text { Variable }\end{array}$ & $\begin{array}{c}\text { Constant } \\
\text { (std. err.) }\end{array}$ & $\begin{array}{c}\text { Statement } \\
\text { (std. err.) }\end{array}$ & $\mathrm{R}^{2}$ & $\begin{array}{c}\text { Number } \\
\text { of Obs. }\end{array}$ \\
\hline $\mathrm{Abs}\left(\mathrm{Z}_{2}\right)$ & $\begin{array}{c}0.044^{* * *} \\
(0.005)\end{array}$ & $\begin{array}{c}0.070^{* * *} \\
(0.014)\end{array}$ & .18 & 138 \\
\hline
\end{tabular}

Note: Regression of absolute value of path factor on a constant and dummy variable indicating presence of an FOMC statement. Heteroskedasticity-consistent standard errors reported in parentheses. ${ }^{* * *}$ denotes significance at 1 percent level. 
reject the hypothesis that FOMC statements and the path factor are unrelated. ${ }^{20}$

In table 4, we report details of the ten largest path factor observations over our sample. Nine of these ten observations (and twentyone of the top twenty-five) correspond to dates on which an FOMC statement accompanied the federal funds rate target decision; moreover, financial market commentary on these dates (as reported in the Credit Markets column of The Wall Street Journal the following day) typically directly attributed the move in the bond market to the specifics of the FOMC statement. Nonetheless, there are a few exceptions to the correspondence between the path factor and FOMC statements, which represent significant changes in financial market expectations regarding the future path of policy that were driven by events other than FOMC statements. For example, on December 20,1994, market participants were reportedly nervous about inflationary pressures arising from output growth overshooting potential (the subject of a speech by Vice Chairman Blinder just a few days before), and the failure of the FOMC to move at the December meeting was reportedly regarded by some participants as perhaps requiring greater tightening down the road (Pesek and Young 1994), leading to larger-than-usual changes in expectations for the future path of policy. ${ }^{21}$

An interesting feature of the path factor is that - in contrast to the target factor - there is evidence that financial markets may take some time to digest its implications. For example, if we regress a wide (one-hour) window measure of the path factor $Z_{2}$ on the tight (thirty-minute) window measure of the factor (both calculated as above), we get an $R^{2}$ of .83 . By contrast, if we perform the same exercise on the target surprise factor $Z_{1}$, we get a much higher $R^{2}$ of .98 (which is consistent with figures 1 and 2). A natural interpretation

\footnotetext{
${ }^{20}$ This finding is similar to a result in Kohn and Sack (2004), who used a simple regression to control for the effects of target surprises, with the residual intended to capture the effects of all other variables, including FOMC statements. They found that the variance of this residual was much higher on days that the FOMC released statements.

${ }^{21}$ We also checked the financial press for each of these dates to see whether the strong response of the path factor on dates without statements could possibly be due to the release of other important news in the same thirty-minute window as the monetary policy announcements. We found no such confounding news releases.
} 


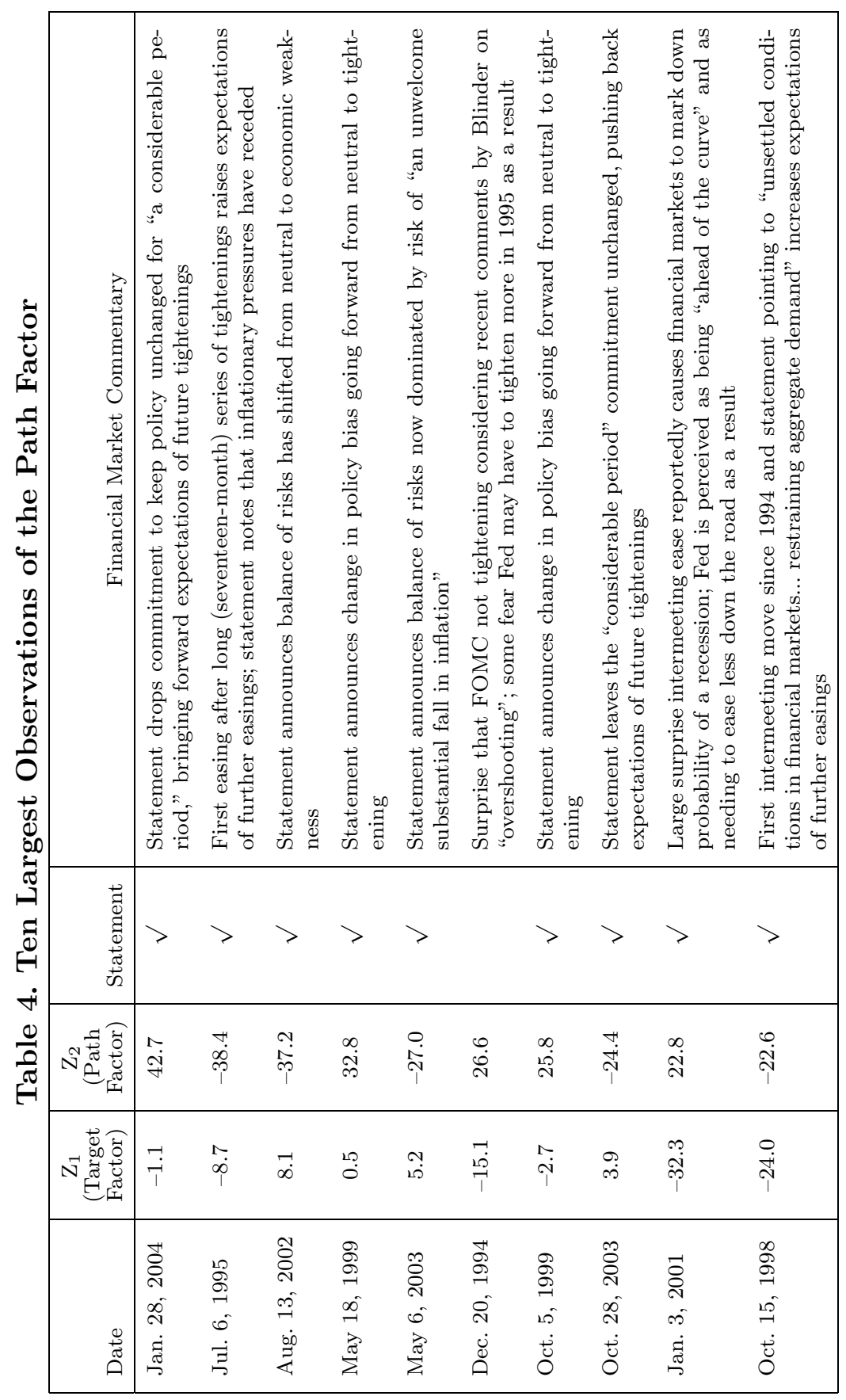


of this finding is that changes in the federal funds rate target itself are immediately and clearly observable to all financial market participants within minutes of the announcement while, by contrast, FOMC statements about the policy and economic outlook typically require time to digest and are subject to a great deal of uncertainty with respect to how they are interpreted by other financial market participants, so that the process of assimilating the information contained in the statements is not instantaneous. Nonetheless, we continue to emphasize our tight window responses in the analysis below because most of the policy information is incorporated within that window and having a narrower window reduces the amount of noise in our left-hand-side variables, increasing the precision of our estimates. $^{22}$

\subsection{The Response of Asset Prices to the Target Factor and Path Factor}

We now estimate the effects of each of these two dimensions of monetary policy announcements on asset prices. For each monetary policy announcement from January 1990 through December 2004, we have estimates of the target factor and path factor components of the announcement and we observe the change in Treasury yields and stock prices in a narrow window bracketing the announcement (the same left-hand-side variables as in section 1). ${ }^{23}$ For each Treasury yield or stock prices, we run the regression

$$
\Delta y_{t}=\alpha+\beta Z_{1, t}+\gamma Z_{2, t}+\varepsilon_{t}
$$

Results are reported in table $5 .^{24}$

\footnotetext{
${ }^{22}$ Robustness tests using the wide window data were in line with the results reported below.

${ }^{23}$ Recall that, due to data availability, we only observe intraday Treasury responses beginning in July 1991.

${ }^{24}$ Because the regressors in table 5 are generated rather than directly observed, we have also computed the standard errors by bootstrapping to capture the additional sampling error associated with the first-stage factor estimation procedure. The statistical significance of all our results was essentially identical whether we used the bootstrapped or asymptotic standard errors. Bootstrap percentiles were based on 1,000 repetitions; in each repetition, we sampled 138 new observations from the data with replacement, took the two largest principal components from the synthetic futures data, rotated and normalized them, and regressed the
} 


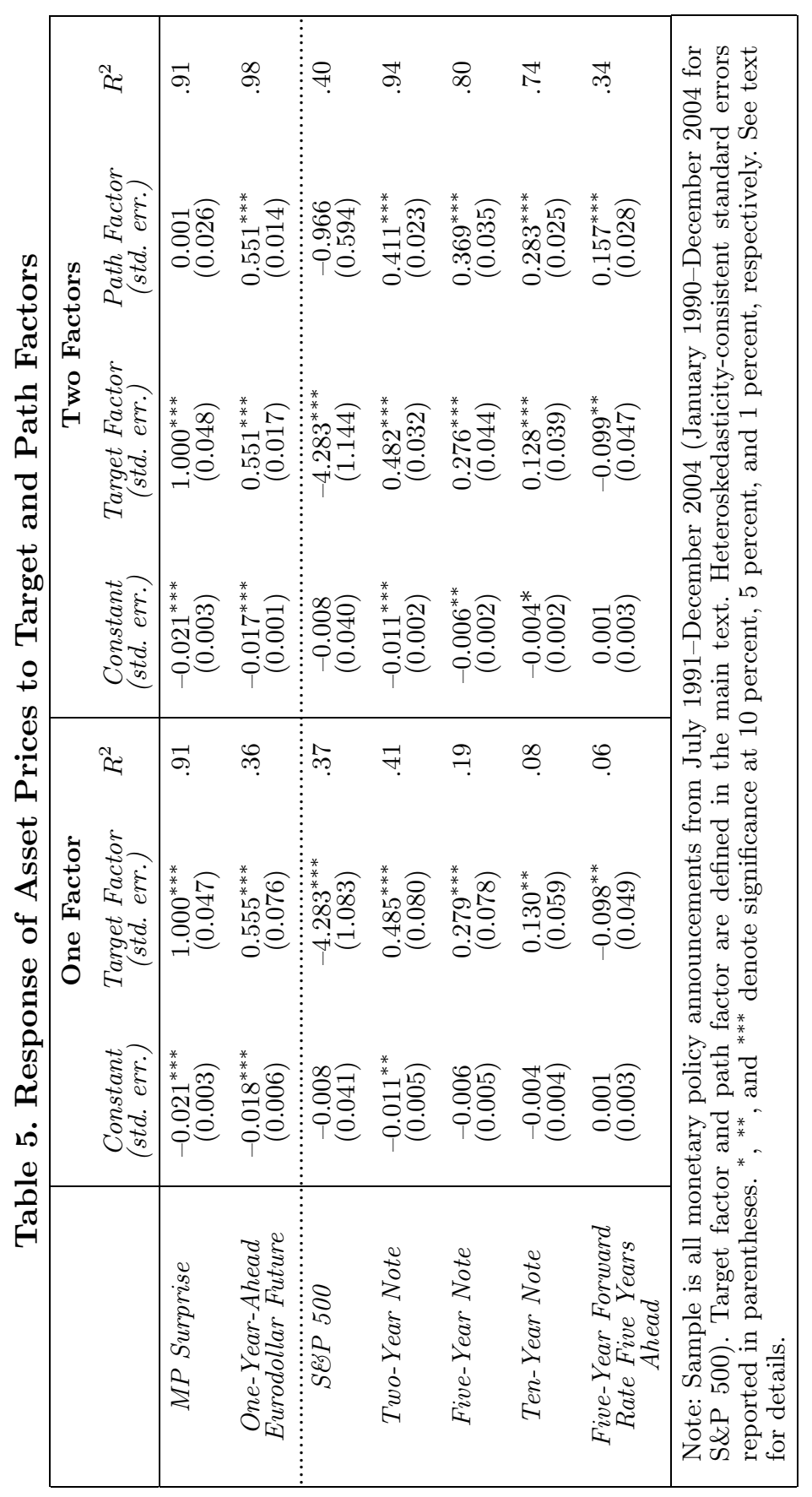


As we would expect from the close correspondence between our target factor and the funds rate target surprises in section 1 (and from the orthogonality of $Z_{2}$ to $Z_{1}$ ), the estimated coefficients on the target factor $\left(Z_{1}\right)$ are very similar to those we estimated previously in table 1 . In particular, we estimate that a 1 percentage point surprise tightening in the federal funds rate leads, on average, to a 4.3 percent decline in the S\&P 500 and increases of 49, 28, and $13 \mathrm{bp}$ in two-, five-, and ten-year Treasury yields, respectively.

The novel feature of table 5, however, is our estimates of the effects of the path factor $\left(Z_{2}\right)$ on asset prices. As can be seen in the table, the effect of this factor on the one-year-ahead eurodollar future rate is the same as the effect of the target factor, by definition. ${ }^{25}$ However, the path factor has effects on the other financial variables that differ considerably from the target factor. In particular, the path factor has a much greater impact on the long end of the yield curve, with a 1 percentage point innovation to the factor causing responses of 37 and $28 \mathrm{bp}$ in five- and ten-year Treasury yields, respectively. Thus, FOMC statements that move one-yearahead policy expectations appear to have much greater effects on the long end of the yield curve than do changes in the federal funds target rate itself, even when they generate the same size movement in one-year-ahead interest rates. Moreover, as can be seen by comparing the $R^{2}$ statistics from the one- and two-factor regressions, the large majority of variation in long-term Treasury yields seems to be due to statements rather than funds rate changes, with two-thirds of the explainable variation in two-year yields, three-fourths of the explainable variation in five-year yields, and nine-tenths of the explainable variation in ten-year yields attributable to the path factor rather than to changes in the federal funds rate target. Thus, by focusing only on the FOMC's decisions regarding the current federal funds rate target, previous authors have been missing by far the most important component of monetary policy decisions, especially

synthetic changes in asset prices on the synthetically generated $Z_{1}$ or $Z_{1}$ and $Z_{2}$. The bootstrapped standard errors are available from the authors upon request.

${ }^{25}$ The path factor is orthogonal to the monetary policy surprise (and the target factor) over our full sample, January 1990-December 2004. The coefficient of the MP Surprise on the path factor in table 5 is not exactly zero because it is reported for the July 1991-December 2004 sample, for comparability to the Treasury yield responses. 
in recent years when target funds rate changes have often been wellanticipated.

By contrast, the effect of changes in the path factor on the stock market appears to be smaller than the effect of changes in the funds rate target, amounting to only about -1 percent for a 1 percentage point innovation. Given the yield curve findings above, this result is somewhat surprising: for longer-maturity Treasury securities, policymakers' statements seem to have much larger effects than changes in the current federal funds rate, but the effect of statements on stock prices, which also have very long durations, is smaller.

One possible explanation for this pattern is that the statements that seem to drive the path factor lead, to a greater extent, to positive revisions in investors' assessment of the future path of output and inflation, consistent with a story first formalized by Romer and Romer (2000). ${ }^{26}$ A large positive realization of the path factor, for example, might be related to a statement suggesting that the FOMC sees greater output or inflation going forward than markets had been expecting. Gürkaynak, Sack, and Swanson (forthcoming) show that long-term yields move substantially and positively in response to positive surprises in macroeconomic data releases for output and inflation; thus, if in fact FOMC statements do reveal information about the future course of these variables, the strong response of long-term yields to the path factor in this paper would be completely consistent with those earlier results. Moreover, to the extent that financial markets revise upward their forecasts of output (and hence earnings and dividends) in response to positive path factor surprises, then the tendency for stocks to fall in response would be muted by the upwardly revised economic outlook.

As a final note, the events of January 4, 2005, provide us with an interesting out-of-sample test of our results. At 2:00 p.m. that day, the FOMC for the first time released the minutes for its previous meeting under a new, accelerated schedule - three weeks before (as opposed to a few days after) the next FOMC meeting. This gives

\footnotetext{
${ }^{26}$ This story has been questioned on the basis of a pure target factor analysis by Faust, Swanson, and Wright (2004b). Those authors find that surprise tightenings in what we call the target factor convey essentially no positive information about the future path of output or inflation. However, as in all of the previous literature, those authors did not consider changes in what we call the path factor, which our results suggest could be more informative about these variables.
} 
the minutes release on that date many of the features of an FOMC statement: for example (and in contrast to speeches or testimony by individual FOMC members), the minutes report the thinking and deliberation of the entire FOMC and have been voted on and approved by the whole committee; moreover, the minutes now provide additional information about the most recent FOMC meeting. In the thirty-minute window around the minutes release on January 4, one-year-ahead eurodollar futures rose $6.5 \mathrm{bp}$, as the minutes were taken to imply greater risks of inflation and funds rate tightening than markets had previously been expecting. Two-, five-, and tenyear Treasury yields increased $4.9,5.0$, and $4.1 \mathrm{bp}$, respectively-very much in line with our estimates of the effects of the path factor in table 5, which would predict changes of 4.8, 4.4, and $3.3 \mathrm{bp}$ for these securities, respectively. The S\&P 500 declined by .49 percent, somewhat larger than the .11 percent decline predicted by table 5 , and the five-to-ten-year forward rate rose by $3.0 \mathrm{bp}$, a bit more than the $1.9 \mathrm{bp}$ predicted by our estimates. Although we cannot rule out the possibility that markets view minutes and FOMC statements as differing in important ways, all of these results are broadly in line with our estimates of the effects of FOMC statements, suggesting that our estimation and identification procedures have been reasonably effective.

\section{Conclusions}

Do central bank actions speak louder than words? We find that the answer to this question is a qualified "no." In particular, we find that viewing the effects of FOMC announcements on financial markets as driven by a single factor - changes in the federal funds rate targetis inadequate. Instead, we find that a second policy factor - one not associated with the current federal funds rate decision of the FOMC but instead with statements that it releases - accounted for more than three-fourths of the explainable variation in the movements of five- and ten-year Treasury yields around FOMC meetings.

We emphasize that our findings do not imply that FOMC statements represent an independent policy tool. In particular, FOMC statements likely exert their effects on financial markets through their influence on financial market expectations of future policy actions. Viewed in this light, our results do not indicate that policy 
actions are secondary so much as that their influence comes earlierwhen investors build in expectations of those actions in response to FOMC statements (and perhaps other events, such as speeches and testimony by FOMC members).

Our findings have important implications for the literature on the effects of monetary policy on asset markets. Indeed, we have shown that previous studies estimating the effects of changes in the federal funds rate on bond yields and stock prices have been missing most of the story. This is especially true in recent years, when FOMC decisions regarding the target for the funds rate have rarely been a surprise and, instead, changes in the wording of FOMC statements typically have been the major driver of financial market responses.

More broadly, our finding that FOMC statements have such significant effects on asset prices suggests that the FOMC has the ability to conduct policy with a substantial degree of commitment to a statecontingent, or conditional, path for the funds rate several quarters or even years into the future. This finding has important implications for the conduct of monetary policy in a low-inflation environmentin particular, even when faced with a low or zero nominal funds rate, our results directly support the theoretical analysis of Reifschneider and Williams (2000) and Eggertsson and Woodford (2003) that the FOMC is largely unhindered in its ability to conduct policy, because it has the ability to manipulate financial market expectations of $f u$ ture policy actions and thereby longer-term interest rates and the economy more generally.

\section{Appendix. Factor Model Rank Test and Estimation}

\section{Testing the Number of Factors}

Let $X$ denote a $T \times n$ matrix of data generated by a factor model:

$$
X=F \Lambda+\eta,
$$

where $F$ is a $T \times k$ matrix of unobserved factors (with $k<n$ ), $\Lambda$ is a $k \times n$ matrix of factor loadings, and $\eta$ is a $T \times n$ matrix of white noise disturbances. We wish to test the hypothesis that $X$ was generated by $k_{0}$ factors against the alternative that $X$ was generated by $k>k_{0}$ factors. We do this by computing the distance between 
the covariance matrix of the data, $X$, and the set of all covariance matrices corresponding to factor models (A1) with $k_{0}$ factors.

The covariance matrix $\Sigma_{X}$ of the data, $X$, has elements given by $\hat{\sigma}_{j k}=(1 / T) \sum_{i}\left(x_{i j}-\bar{x}_{j}\right)\left(x_{i k}-\bar{x}_{k}\right)$. To compute the Wald statistic, below, we also need to know the sampling uncertainty surrounding the $\hat{\sigma}_{j k}$. This is given by:

$$
\begin{aligned}
\operatorname{Cov}\left(\hat{\sigma}_{j k}, \hat{\sigma}_{l m}\right)=\left(1 / T^{2}\right) & \sum_{i}\left[\left(x_{i j}-\bar{x}_{j}\right)\left(x_{i k}-\bar{x}_{k}\right)-\hat{\sigma}_{j k}\right] \\
& \times\left[\left(x_{i l}-\bar{x}_{l}\right)\left(x_{i m}-\bar{x}_{m}\right)-\hat{\sigma}_{l m}\right] .
\end{aligned}
$$

The covariance matrix of the factor model (A1) is given by $\Lambda^{\prime} \Lambda+\Sigma_{\eta}$. To compute the distance between the two, we stack the elements of $\Sigma_{X}$ and $\Lambda^{\prime} \Lambda+\Sigma_{\eta}$ into vectors and normalize the difference, $\operatorname{vech}\left(\Sigma_{X}\right)-\operatorname{vech}\left(\Lambda^{\prime} \Lambda+\Sigma_{\eta}\right)$, by $\operatorname{Cov}\left(\operatorname{vech}\left(\Sigma_{X}\right)\right)$, whose elements are given by (A2):

$$
W=\left[\operatorname{vech}\left(\Sigma_{X}\right)-\operatorname{vech}\left(\Lambda^{\prime} \Lambda+\Sigma_{\eta}\right)\right]^{\prime} \hat{\Omega}^{-1}\left[\operatorname{vech}\left(\Sigma_{X}\right)-\operatorname{vech}\left(\Lambda^{\prime} \Lambda+\Sigma_{\eta}\right)\right],
$$

where $\hat{\Omega}=\operatorname{Cov}\left(\operatorname{vech}\left(\Sigma_{X}\right)\right)$. We search over all possible factor loadings $\Lambda$ ( $n k_{0}$ parameters) and white noise variances $\Sigma_{\eta}$ ( $n$ parameters) to find the minimum distance (A3). Under the null hypothesis, this is a Wald statistic with limiting $\chi^{2}$ distribution on $n(n+1) / 2-$ $\left(n k_{0}+n\right)+k_{0}\left(k_{0}-1\right) / 2$ degrees of freedom (the last term comes from the fact that there are $k_{0}\left(k_{0}-1\right) / 2$ possible rotations of the unobserved factors $F$, and hence $\Lambda$, which all yield the same observable model). The Matlab code that performs this factor test is available from the authors upon request.

\section{Factor Estimation}

To estimate the unobserved factors $F$, let $X$ be the matrix with 138 rows corresponding to monetary policy announcements and five columns corresponding to futures contracts with one year or less to maturity. The third through fifth columns of $X$ are the changes in price of the second, third, and fourth eurodollar futures contracts, which have $1.5,2.5$, and 3.5 quarters to expiration on average (eurodollar futures have expiration dates that lie about two weeks before 
the end of each quarter). ${ }^{27}$ The first two columns of $X$ are essentially the changes in the current-month and three-month-ahead federal funds futures contracts, but contain a scaling adjustment to account for the timing of FOMC meetings within those months, as follows.

Federal funds futures have a payout that is based on the average effective federal funds rate that prevails over the calendar month specified in the contract. Thus, immediately before an FOMC meeting, at time $t-\Delta t$, the implied rate from the current-month federal funds future contract, $f f 1$, is largely a weighted average of the federal funds rate that has prevailed so far in the month, $r_{0}$, and the rate that is expected to prevail for the reminder of the month, $r_{1}:^{28}$

$$
f f 1_{t-\Delta t}=\frac{d 1}{D 1} r_{0}+\frac{D 1-d 1}{D 1} E_{t-\Delta t}\left(r_{1}\right)+\rho 1_{t-\Delta t}
$$

where $d 1$ denotes the day of the FOMC meeting, $D 1$ is the number of days in the month, and $\rho 1$ denotes any term or risk premium that may be present in the contract. Then, by leading this equation to time $t$ (twenty minutes after the policy announcement) and differencing, the surprise component of the change in the federal funds rate target, which we call $m p 1$, is given by ${ }^{29}$

$$
m p 1_{t}=\left(f f 1_{t}-f f 1_{t-\Delta t}\right) \frac{D 1}{D 1-d 1} .
$$

Note that to interpret (A5) as the surprise change in monetary policy expectations, we need to assume that the change in the risk

\footnotetext{
${ }^{27}$ Thus, the second eurodollar futures contract can have as little as one quarter plus one day to expiration and as much as two quarters to expiration, with an average horizon of 1.5 quarters over our sample. On expiration, eurodollar futures settle based on the spot ninety-day eurodollar rate, which is closely tied to expectations for the federal funds rate over the subsequent ninety-day period. Thus, these three eurodollar futures contracts are related to federal funds rate expectations from 1.5-2.5, 2.5-3.5, and 3.5-4.5 quarters ahead, respectively.

${ }^{28}$ For simplicity, assume that federal funds rate is always equal to the target rate set by the FOMC, so that we do not have to differentiate between the target and actual rates. This has no impact on the surprise measures due to the differencing involved.

${ }^{29}$ Kuttner (2001) also uses this method. For FOMC meetings that occur very late in the month (i.e., in the last seven days of the month), we use the unscaled change in the next-month federal funds futures contract to avoid multiplying by a very large scale factor in (A5), which could unduly magnify changes in bid-ask spreads or other factors, since federal funds futures are only priced to the nearest half basis point.
} 
premium $\rho$ in this narrow window of time is small in comparison to the change in expectations itself. Piazzesi and Swanson (2004) provide some evidence that this assumption is not inconsistent with the data.

We can apply a similar procedure to measure the change in expectations about $r_{2}$, the federal funds rate target that will prevail after the second FOMC meeting from now. Let ff 2 denote the federal funds futures rate for the month containing the second FOMC meeting (typically the three-month-ahead contract). Then

$$
f f 2_{t-\Delta t}=\frac{d 2}{D 2} E_{t-\Delta t}\left(r_{1}\right)+\frac{D 2-d 2}{D 2} E_{t-\Delta t}\left(r_{2}\right)+\rho 2_{t-\Delta t},
$$

where $d 2$ and $D 2$ are the day of that FOMC meeting and the number of days in the month containing that FOMC meeting, respectively, and $\rho 2$ denotes any risk premium in the contract. By leading this equation to time $t$ and differencing, the change in expectations for that second FOMC meeting, which we call $m p 2$, is given by

$$
m p 2_{t}=\left[\left(f f 2_{t}-f f 2_{t-\Delta t}\right)-\frac{d 2}{D 2} m p 1_{t}\right] \frac{D 2}{D 2-d 2} .
$$

Additional details can be obtained from various sources. ${ }^{30}$

As described in section 2, we decompose $X$ into its principal components after normalizing each column to have zero mean and unit variance. We let $F_{1}$ and $F_{2}$ denote the first two principal components of $X$, and normalize each of them to have unit variance.

To allow for a more structural interpretation of these unobserved factors, we rotate them so that the first factor corresponds to surprise changes in the current federal funds rate target and the second factor corresponds to moves in interest rate expectations over the coming year that are not driven by changes in the current funds rate. In other words, we define a $138 \times 2$ matrix $Z$ by

$$
Z=F U
$$

\footnotetext{
${ }^{30}$ Gürkaynak (2005) discusses measuring policy expectations and surprises at horizons farther ahead than the current meeting; Gürkaynak, Sack, and Swanson (2002) show that federal funds futures are the best financial market predictors of the federal funds rate with the smallest average term premium; Piazzesi and Swanson (2004) estimate to what extent risk premia in these markets vary over time; and Kuttner (2001) discusses the construction and some uses of $m p 1$.
} 
where

$$
U=\left[\begin{array}{ll}
\alpha_{1} & \beta_{1} \\
\alpha_{2} & \beta_{2}
\end{array}\right],
$$

and where $U$ is identified by four restrictions. First, the columns of $U$ are normalized to have unit length (which normalizes $Z_{1}$ and $Z_{2}$ to have unit variance). Second, the new factors $Z_{1}$ and $Z_{2}$ should remain orthogonal to each other:

$$
E\left(Z_{1} Z_{2}\right)=\alpha_{1} \beta_{1}+\alpha_{2} \beta_{2}=0 .
$$

Lastly, we impose the restriction that $Z_{2}$ does not influence the current policy surprise, $m p 1$, as follows. Let $\gamma_{1}$ and $\gamma_{2}$ denote the (known) loadings of $m p 1$ on $F_{1}$ and $F_{2}$, respectively. Since

$$
\begin{aligned}
& F_{1}=\frac{1}{\alpha_{1} \beta_{2}-\alpha_{2} \beta_{1}}\left[\beta_{2} Z_{1}-\alpha_{2} Z_{2}\right], \\
& F_{2}=\frac{1}{\alpha_{1} \beta_{2}-\alpha_{2} \beta_{1}}\left[\alpha_{1} Z_{2}-\beta_{1} Z_{1}\right],
\end{aligned}
$$

it follows that:

$$
\gamma_{2} \alpha_{1}-\gamma_{1} \alpha_{2}=0
$$

which is the final restriction. It is then easy to solve for the unique matrix $U$ satisfying these restrictions.

Finally, as noted in section 2 , we rescale $Z_{1}$ and $Z_{2}$ so that $Z_{1}$ moves the current policy surprise $m p 1$ one-for-one and $Z_{2}$ has the same magnitude effect on the year-ahead eurodollar futures rate as $Z_{1}$ has on that rate (about $55.1 \mathrm{bp}$ ).

\section{References}

Bernanke, Ben, and Kenneth Kuttner. Forthcoming. "What Explains the Stock Market's Reaction to Federal Reserve Policy?" Journal of Finance.

Bernanke, Ben, Vincent Reinhart, and Brian Sack. 2004. "Monetary Policy Alternatives at the Zero Bound: An Empirical Assessment." Brookings Papers on Economic Activity 2:1-100.

Cochrane, John, and Monika Piazzesi. 2002. "The Fed and Interest Rates: A High Frequency Identification." American Economic Review Papers and Proceedings 92:90-101. 
Cook, Timothy, and Thomas Hahn. 1989. "The Effect of Changes in the Federal Funds Rate Target on Market Interest Rates in the 1970s." Journal of Monetary Economics 24:331-51.

Cragg, John G., and Stephen G. Donald. 1997. "Inferring the Rank of a Matrix." Journal of Econometrics 76:223-50.

Eggertsson, Gauti, and Michael Woodford. 2003. "The Zero Bound on Short-Term Interest Rates and Optimal Monetary Policy." Brookings Papers on Economic Activity 1:139-211.

Ellingsen, Tore, and Ulf Soderstrom. 2003. "Monetary Policy and the Bond Market." Unpublished Manuscript, Bocconi University.

Evans, Charles, and David Marshall. 1998. "Monetary Policy and the Term Structure of Nominal Interest Rates: Evidence and Theory." Carnegie-Rochester Conference Series on Public Policy 49:53-111.

Faust, Jon, Eric Swanson, and Jonathan Wright. 2004a. "Identifying VARs Based on High-Frequency Futures Data." Journal of Monetary Economics 51 (6): 1077-1317.

Faust, Jon, Eric Swanson, and Jonathan Wright. 2004b. "Do Federal Reserve Policy Surprises Reveal Superior Information About the Economy?" Contributions to Macroeconomics 4 (1): Article 10.

Gürkaynak, Refet. 2005. "Using Federal Funds Futures Contracts for Monetary Policy Analysis." Working Paper, Federal Reserve Board.

Gürkaynak, Refet, Brian Sack, and Eric Swanson. 2002. "MarketBased Measures of Monetary Policy Expectations." Federal Reserve Board Finance and Economics Discussion Series 200240.

Gürkaynak, Refet, Brian Sack, and Eric Swanson. Forthcoming. "The Sensitivity of Long-Term Interest Rates to Economic News: Evidence and Implications for Macroeconomic Models." American Economic Review.

Ip, Greg. 2004. "Fed Clears Way For Future Rise In Interest Rates." The Wall Street Journal, January 29, A1.

Kohn, Donald, and Brian Sack. 2004. "Central Bank Talk: Does It Matter and Why?" In Macroeconomics, Monetary Policy, and Financial Stability. Ottawa: Bank of Canada.

Krueger, Joel T., and Kenneth N. Kuttner. 1996. "The Fed Funds Futures Rate as a Predictor of Federal Reserve Policy." Journal of Futures Markets 16:865-79. 
Kuttner, Kenneth. 2001. "Monetary Policy Surprises and Interest Rates: Evidence from the Fed Funds Futures Market." Journal of Monetary Economics, 523-44.

Kuttner, Kenneth. 2003. "The Revelation of Funds Rate Changes, 1989-92: What Did the Markets Know and When Did They Know It?" Unpublished Manuscript, Oberlin College.

Leeper, Eric, Christopher Sims, and Tao Zha. 1996. "What Does Monetary Policy Do?" Brookings Papers on Economic Activity $2: 1-63$.

Pesek, William, and Lauren Young. 1994. "Bond Prices Finish Little Changed After Fed Decides to Keep Rates at Their Current Levels." The Wall Street Journal, December 21, C22.

Piazzesi, Monika, and Eric Swanson. 2004. "Futures Rates as RiskAdjusted Forecasts of Monetary Policy." NBER Working Paper No. 10547.

Reifschneider, David, and John Williams. 2000. "Three Lessons for Monetary Policy in a Low-Inflation Era." Journal of Money, Credit, and Banking 32:936-66.

Rigobon, Roberto, and Brian Sack. 2004. "The Impact of Monetary Policy on Asset Prices." Journal of Monetary Economics 51:1553-75.

Rigobon, Roberto, and Brian Sack. 2003. "Measuring the Reaction of Monetary Policy to the Stock Market." Quarterly Journal of Economics 118:639-69.

Romer, Christina, and David Romer. 2000. "Federal Reserve Information and the Behavior of Interest Rates." American Economic Review 90:429-57.

Rudebusch, Glenn. 1998. "Do Measures of Monetary Policy in a VAR Make Sense?" International Economic Review 39:907-31.

Shiller, Robert, John Campbell, and Kermit Schoenholtz. 1983. "Forward Rates and Future Policy: Interpreting the Term Structure of Interest Rates." Brookings Papers on Economic Activity 1:173217. 